\title{
Hormonal regulation of glutathione S-transferase expression in co-cultured adult rat hepatocytes
}

\author{
S Coecke, T Vanhaecke, A Foriers, I R Phillips ${ }^{1}$, A Vercruysse, \\ E A Shephard ${ }^{2}$ and V Rogiers \\ Department of Toxicology, Vrije Universiteit Brussel, Laarbeeklaan 103, B-1090 Brussels, Belgium \\ ${ }^{1}$ Molecular and Cellular Biology, Division of Biomedical Sciences, Queen Mary and Westfield College, University of London, Mile End Road, \\ London E1 4NS, UK \\ ${ }^{2}$ Department of Biochemistry and Molecular Biology, University College London, Gower Street, London WC1E 6BT, UK \\ (Requests for offprints should be addressed to T Vanhaecke; Email: tamaravh@fafy.vub.ac.be)
}

\begin{abstract}
Glutathione S-transferases (GSTs) are subject to regulation by thyroid and sex hormones and by GH. We have used an in vitro experimental system comprising adult rat hepatocytes co-cultured with rat liver epithelial cells of primitive biliary origin, to distinguish between direct and indirect effects of various hormones on GSTs; to identify the GST subunits affected by individual hormones; and to investigate the level at which the hormones act. Triiodothyronine $\left(\mathrm{T}_{3}\right)$, thyroxine $\left(\mathrm{T}_{4}\right)$ and $17 \beta$-oestradiol $\left(\mathrm{OE}_{2}\right)$ reduced GST activities, whereas testosterone, dihydrotestosterone, and human growth hormone (hGH) had little effect on total GST activity. HPLC separation of
\end{abstract}

the various GST subunits revealed that $T_{3}$ and $T_{4}$ reduced total GST content, in particular the abundance of subunits M1 and M2. The amount of the Pi-class subunit P1 was reduced by $\mathrm{OE}_{2}$. Treatment of the co-cultured cells with this hormone altered the GST subunit profile to one that is more similar to that observed in freshly isolated hepatocytes. Analysis of mRNAs demonstrated that some of the hormones act at a pre-translational level, whereas others act at a translational or post-translational level to regulate the expression of various GST subunits.

Journal of Endocrinology (2000) 166, 363-371

\section{Introduction}

Cytosolic glutathione S-transferases (GSTs; EC 2:5·1·18) constitute a family of dimeric proteins consisting of two identical or closely related subunits belonging to the same class. A species-independent scheme of classifying these subunits into Alpha, $\mathrm{Mu}, \mathrm{Pi}$, Theta and Sigma classes has been widely accepted (Mannervik et al. 1985, Tsuchida \& Sato 1992, Hayes \& Pulford 1995). GSTs play a role in the detoxification of electrophilic xenobiotics or electrophilic metabolites of xenobiotics produced by mixed-function oxygenases (Mannervik \& Danielson 1988, Pickett \& Lu 1989, Hayes \& Pulford 1995). In addition, GST proteins control the uptake and transport of numerous hydrophobic endogenous compounds, including bilirubin, glucocorticoids, steroids and thyroid hormones, via non-covalent glutathione (GSH)-dependent binding to GST (Listowsky et al. 1988, Ishigaki et al. 1989, Wilce \& Parker 1994).

Two types of GST inhibitors are known. Irreversible inhibitors, such as halogenated quinones, covalently modify a cysteine residue near, or in, the active site of the GST enzyme (Vos \& Van Bladeren 1990). Reversible inhibitors, on the other hand, act through non-covalent binding and include, among others, thyroid hormones, as mentioned above (Boyer et al. 1984, Listowsky et al. 1988).

Transcriptional activation by exogenous substances has been best documented for the GSTA1/2 subunit gene of the rat. Several enhancer elements, including the xenobiotic-responsive element (XRE), the antioxidantresponsive element (ARE), the glucocorticoid-responsive element (GRE) and the barbiturate-responsive element (Barbie box) have been identified in the $5^{\prime}$-flanking regulatory region of this gene and are responsible for its induction by polycyclic aromatic hydrocarbons including 3 -methylcholanthrene and $\beta$-naphtoflavone, products of oxidative stress, dexamethasone and phenobarbital respectively (Rushmore et al. 1991, Hayes \& Pulford 1995). With respect to the endogenous regulation of GST expression, it is known that adrenocorticotrophic (Mankowitz et al. 1990), growth (Staffas et al. 1992), thyroid (Kelley \& Bjeldanes 1995, Beckett et al. 1988) and steroid hormones (Hatayama et al. 1986) are involved. At the regulatory level, it has been shown that insulin induces the transcription of the human GSTP1 gene via one of the SP-1 sites (GC/box) in the $5^{\prime}$-flanking regulatory region, whilst retinoic acid suppresses hGSTP1 expression through the AP-1 site (Xia et al. 1993, 1996). However, compared 
with xenobiotic-mediated GST regulation, the endogenous hormonal control of GST expression has received much less attention.

Several aspects of both endogenous and exogenous hepatic GST regulation have been mainly studied in vivo (McLellan \& Hayes 1987, Scott \& Kirsh 1987, Li \& Tu 1989, Meyer et al. 1991, 1993, Singhal et al. $1992 a, b$, Hatayama et al. 1993). It is, however, generally agreed that it is difficult to make a distinction between the direct and indirect effects of hormones and drugs administered in vivo. Such a discrimination is more feasible in vitro (Gebhardt et al. 1990, Vind et al. 1992). At present, no ideal hepatocyte culture system exists. However, previous work by our group has shown that hepatocytes co-cultured with rat-liver epithelial cells of primitive biliary origin maintain the expression of many differentiated liver functions and may provide a useful model for studying enzyme regulation (Vandenberghe et al. 1988a, 1991, Rogiers et al. 1990, Akrawi et al. 1993, Coecke et al. 1993, Rogiers 1993, Rogiers \& Vercruysse 1993). In this paper, we report the use of adult rat hepatocytes co-cultured with rat-liver epithelial cells of biliary origin, to distinguish between direct and indirect effects of various hormones on GSTs, to identify the GST subunits affected by individual hormones, and to investigate the level at which each hormone acts.

\section{Materials and Methods}

\section{Materials}

Crude collagenase type I, bovine serum albumin (bsan) (fraction V), bovine insulin, 1-chloro-2,4-dinitrobenzene (CDNB), hGH (2 IU/mg), GSH and epoxy-activated Sepharose 6B were obtained from the Sigma Chemical Co. (St Louis, MO, USA). All culture media, foetal calf serum and trypsin-EDTA solution were obtained from Gibco (Brussels, Belgium). 5 Alpha-dihydrotestosterone $(5 \alpha-\mathrm{DHT})$ was purchased from Janssen Chimica (Geel, Belgium). $\mathrm{OE}_{2}, \mathrm{~T}_{3}$ and $\mathrm{T}_{4}$ were obtained from Fluka Chemie (Bornem, Belgium) and testosterone was purchased from K\&K Rare and Fine Chemicals (Asse, Belgium). 1,2-Dichloro-4-nitrobenzene (DCNB) was from Merck-Belgolabo (Darmstadt, Germany). RNAzol B was purchased from A.M.S. Biotechnology (Witney, UK). The Klenow fragment of Escherichia coli DNA polymerase was from Pharmacia Biotech Ltd (Milton Keynes, UK). All other chemicals were of reagent grade and were purchased from general commercial sources.

\section{cDNA probes}

Full-length cDNA probes complementary to GST A1/2 mRNA (cross-hybridization to GST A3 mRNA occurs), GST M1 mRNA (cross-hybridization to GST M2
mRNA occurs) and GST P1 were the kind gifts of Dr S Pemble (University College London, London, UK) (Pemble et al. 1986).

\section{Preparation of hepatocyte cultures and cytosolic fractions}

Hepatocytes were isolated from outbred adult male Sprague-Dawley rats (specific pathogen-free Carworth Farms Elias, 15 weeks old, $350 \mathrm{~g}$ ), obtained from Iffa Credo (Brussels, Belgium), as described by De Smet et al. (1998). Cell integrity was tested by trypan blue exclusion and ranged from 85 to $95 \%$. Rat-liver epithelial cells were obtained by trypsinization of the livers of 10-day-old Sprague-Dawley rats (Williams \& Gunn 1974) and were used between their 20th and 30th passages, as described in detail by Vanhaecke et al. (1998). Twenty-four hours after cell plating, the cultures were incubated with serum-free medium containing testosterone, $5 \alpha-\mathrm{DHT}, \mathrm{OE}_{2}, \mathrm{~T}_{3}$ or $\mathrm{T}_{4}$ at a final concentration of $10 \mu \mathrm{M}$. Such high concentrations are required because of the high degradation rate of these hormones in co-cultures (Coecke et al. 1998). The cultures also contained the hormone vehicle ethanol, at a concentration of $0 \cdot 1 \%(\mathrm{v} / \mathrm{v})$. Only in the case of $\mathrm{T}_{4}$ addition was a concentration of $0 \cdot 4 \%(\mathrm{v} / \mathrm{v})$ used. For treatment of cells with hGH, the hormone was dissolved in phosphate-buffered saline (PBS) solution and added to the cells to a final concentration of $0.1 \mu \mathrm{g} / \mathrm{ml}$. In this case, the vehicle was present at a final concentration of $0 \cdot 1 \%$. Appropriate control cultures were run and contained $0 \cdot 1 \%$ ethanol, $0 \cdot 4 \%$ ethanol or $0 \cdot 1 \%$ PBS.

Cytosolic fractions from freshly isolated hepatocytes (T0) and co-cultures were prepared as described by Johnson et al. (1992). Storage at $-80{ }^{\circ} \mathrm{C}$ for three months did not modify GST activity (Vandenberghe et al. 1988a, and our own observations).

\section{Enzyme and protein assays}

Total and Mu-class M1-1 and M1-2 GST activities towards CDNB and DCNB respectively, were assayed according to Habig et al. (1974). The protein content of the cytosolic fractions was determined by the method of Bradford (1976), using a protein assay kit (Bio-Rad, Brussels, Belgium) with bovine serum as a standard.

\section{Isolation and separation of GST subunits}

GSTs were isolated from cytosolic fractions by affinity chromatography as previously described (Vandenberghe et al. 1988b). The separation and quantification of GST subunits was carried out according to Vandenberghe et al. (1990), using an LC10 system (Shimadzu, Berelux, 's-Hertogen-bosch, Netherlands) with a Prolinea 4/33 HPLC-dedicated integrator (Compaq, Houston, TX, USA). The GST subunits were identified by comparison 
of the retention time obtained for the individual peaks with those of purified GST subunits and by comparison of the patterns generated with characteristic extrahepatic GST profiles and previously published GST HPLC profiles (Hiratsuka et al. 1990, Vandenberghe et al. 1990, Meyer et al. 1991, Johnson et al. 1990, 1992, 1993, Kispert et al. 1989, Meyer et al. 1989). GST subunits were quantified using peak areas of the respective subunits from HPLC, together with molecular masses (Mannervik \& Danielson 1988) and molar extinction coefficients at $214 \mathrm{~nm}$, as given by Johnson et al. (1992). The concentrations of the individual subunits were expressed as $\mu \mathrm{g}$ per mg cytosolic protein.

A peak with a retention time of 11 min was found to be due to the TRIS-GSH buffer used to elute the column.

\section{RNA isolation and Northern blots}

RNA was isolated from freshly isolated and co-cultured hepatocytes using RNAzol B and the procedure described by Chomczynski \& Sacchi (1987). Equal amounts of total RNA (15 $\mu \mathrm{g}$ per lane) were size-fractionated by electrophoresis in a denaturing formaldehyde agarose gel and transferred to a nylon membrane (Hybond- $\mathrm{N}^{+}$, Amersham, Buckinghamshire, UK) (Fourney et al. 1988). Filters were prehybridized and hybridized with full-length $\left[\alpha^{32} \mathrm{P}\right] \mathrm{dCTP}-\mathrm{labelled}$ GST cDNA probes according to Feinberg \& Vogelstein (1983). After hybridization, filters were washed, dried, and autoradiographed at $-80{ }^{\circ} \mathrm{C}$ using RX-NIF X-ray films (Fuji Film, USA Inc). Hybridization signals were quantified by scanning densitometry using a Bio-Rad densitometer (Model GS670). To correct for any unequal loading of the RNA, signals were normalized with respect to the 28S rRNA content.

\section{Statistical analysis}

Statistical evaluation of the differences obtained was achieved by Student's $t$-tests, using the Software Package of the Social Sciences, SPSS/PC+ (Norusis 1986). $P<0 \cdot 05$ was the set level of significance.

\section{Results}

Ability of freshly isolated hepatocytes to express GST activities

During the process of isolation, hepatocytes lose some of the differentiated functions associated with the intact liver in vivo (Mertens et al. 1993a). It was thus necessary to ensure that isolated hepatocytes for use in the co-culture system maintained levels of GST activities similar to those observed in vivo (Croci \& Williams 1985, Vandenberghe et al. 1988a). Therefore, suspensions of freshly isolated hepatocytes were used for co-cultures only if they contained GST activities with respect to CDNB and DCNB

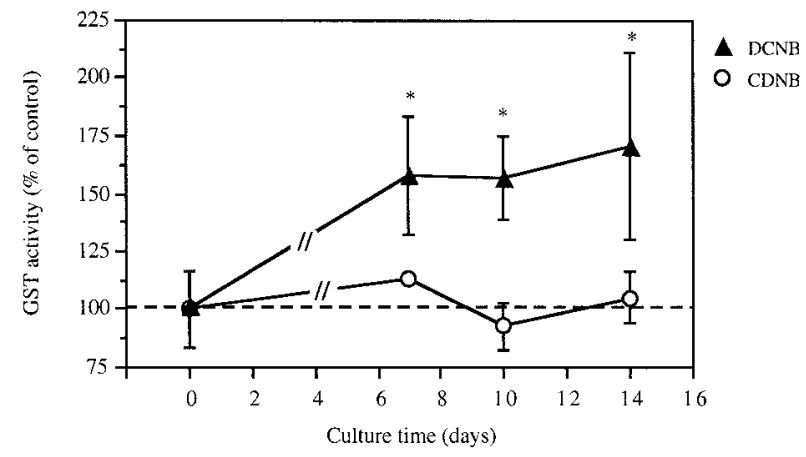

Figure 1 GST activity towards CDNB and DCNB in co-cultures of adult rat hepatocytes maintained in serum-free medium. Each point plotted represents the average of values obtained from three independent co-cultures of hepatocytes and is expressed as a percentage of the GST activities towards CDNB and DCNB obtained for freshly isolated hepatocytes (broken line; $1 \cdot 263 \pm 0.246$ and $0.037 \pm 0.006 U$ per mg cytosolic protein respectively). The bars represent standard deviation. *Significantly different from freshly isolated hepatocytes according to a paired Student's t-test $(P<0 \cdot 05)$.

of at least $1.2 \mu \mathrm{mol} / \mathrm{min} / \mathrm{mg}$ cytosolic protein and $35 \mathrm{nmol} / \mathrm{min} / \mathrm{mg}$ cytosolic protein respectively. Cells that met these criteria maintained constant levels of GST activities after 7-14 days in culture, thus providing a suitable system for studying hormonal regulation of GST expression (Fig. 1).

\section{Effect of hormones on GST activities}

Administration of either $\mathrm{OE}_{2}, \mathrm{~T}_{3}$ or $\mathrm{T}_{4}$ for 10 days in co-culture reduced GST activity towards CDNB and DCNB by approximately 30 and $40 \%$ respectively $(P<0 \cdot 05)$. Addition of hGH to the co-cultured hepatocytes reduced the activity of isoenzyme M1-1/M1-2 $(P<0 \cdot 05)$, but had no significant effects on total GST activity. Neither testosterone nor $5 \alpha$-DHT had a significant effect on either total GST or isoenzyme M1-1/M1-2 activity. As ethanol, used as a vehicle for all the hormones tested except $\mathrm{GH}$, is known to induce the activities of certain enzymes involved in the metabolism of xenobiotics (Skett \& Paterson 1985, Okey 1990), its effect on GST activities in co-cultured hepatocytes was investigated. Ethanol at a final concentration of $0 \cdot 1 \%$ (equivalent to that present in the medium during treatment of cells with testosterone, $5 \alpha-\mathrm{DHT}, \mathrm{OE}_{2}$ or $\mathrm{T}_{3}$ ) had no significant effects on either total or Mu-class M1-1/M1-2 GST activities. In contrast, $0 \cdot 4 \%$ ethanol, equivalent to the final concentration present during treatment of cells with $\mathrm{T}_{4}$, increased GST activity with respect to CDNB by $35 \%$ $(P<0 \cdot 05)$. The small increase in GST activities obtained with DCNB as a substrate was not significant. In order to exclude any misleading conclusions because of possible interference of the vehicle with GST results, 


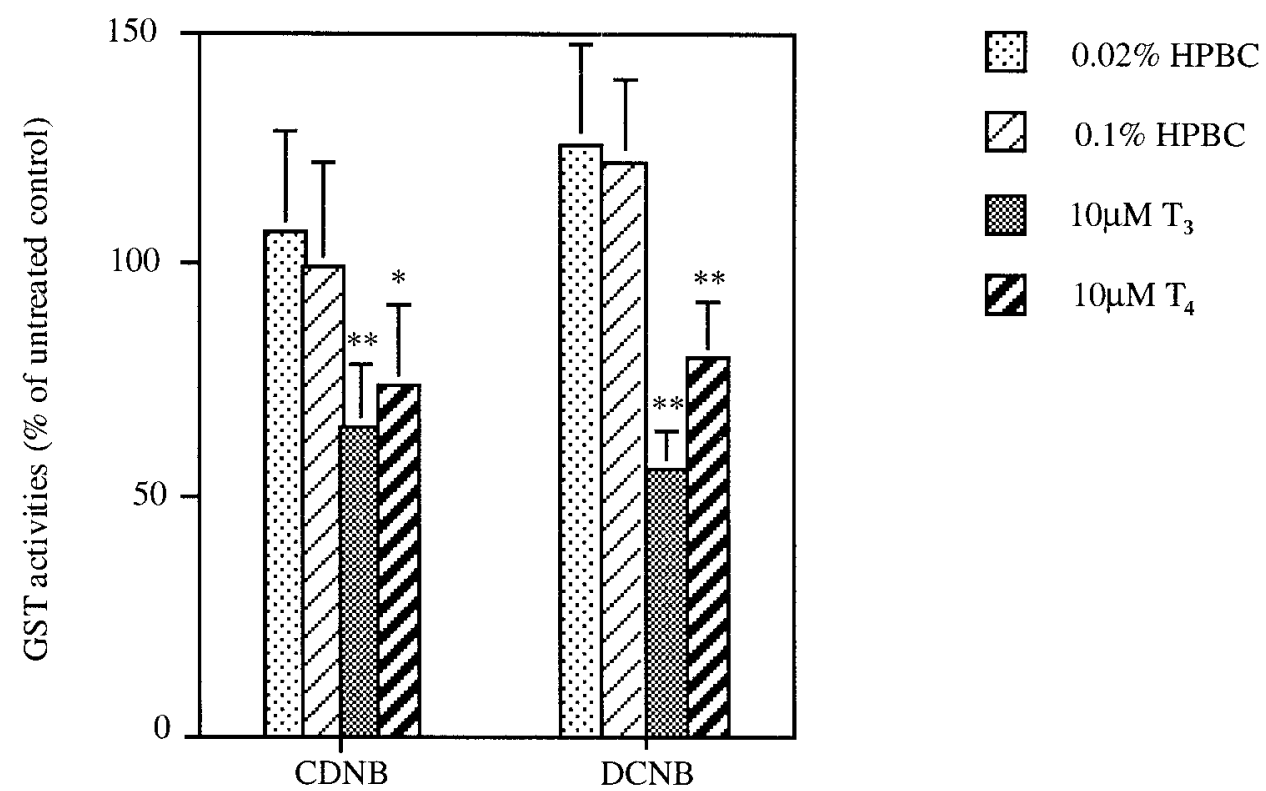

Figure 2 Effect of $T_{3}$ and $T_{4}$ delivery in HPBC on GST activity towards CDNB and DCNB in co-cultures of adult rat hepatocytes. The hormonal concentration was $10 \mu \mathrm{M} \mathrm{T}_{3}$ and $\mathrm{T}_{4}$ were taken up in 0.02 and $0 \cdot 10 \%(\mathrm{w} / \mathrm{v})$ HPBC respectively. Each value represents the average \pm standard deviation of values obtained from three independent co-cultures of hepatocytes. The results are expressed as a percentage of the GST activities towards CDNB and DCNB obtained for 10-day-old, untreated, control co-cultures $\left(0.397 \pm 0.089\right.$ and $0.017 \pm 0.004 \mathrm{U}$ per $\mathrm{mg}$ cytosolic protein respectively). ${ }^{*} P<0.05$ or ${ }^{* *} P<0 \cdot 01$ for significant difference from 10-day-old, untreated, co-cultures according to a paired Student's $t$-test.

hydroxypropyl- $\beta$-cyclodextrin (HPBC) was also used to deliver $\mathrm{T}_{3}$ and $\mathrm{T}_{4}$. When $0 \cdot 1$ and $0 \cdot 4 \%(\mathrm{v} / \mathrm{v})$ ethanol were replaced by $0 \cdot 02$ and $0 \cdot 1 \%(\mathrm{w} / \mathrm{v})$ HPBC to deliver $\mathrm{T}_{3}$ and $\mathrm{T}_{4}$ to the cultured cells respectively, no statistically significant effects on GST activities towards CDNB and DCNB could be observed (Fig. 2). Moreover, $\mathrm{T}_{3}$ and $\mathrm{T}_{4}$ administered via HPBC reduced total and Mu-class GST activities by approximately $30-40 \%$, which corresponds well with our observations on GST activities with ethanol as a solvent. These findings indicate that co-cultured unexposed cells that are treated with appropriate concentrations of ethanol represent the correct controls. Consequently, the corresponding results of hormone-exposed and non-exposed cells used to calculate hormonal effects on co-cultured cells led to relevant conclusions.

\section{Effect of hormones on GST subunit profiles}

The GST subunit compositions of cytosolic fractions obtained from freshly isolated rat hepatocytes (T0) and from co-cultured hepatocytes in the presence or absence of various hormones are given in Table 1 . The total content of GST protein present in freshly isolated hepatocytes was $76 \cdot 3 \pm 6 \cdot 3 \mu \mathrm{g}$ per $\mathrm{mg}$ cytosolic protein. This comprised similar amounts of Alpha- and $\mathrm{Mu}$-class proteins. After hepatocytes had been co-cultured for 10 days in a serumfree medium, the total content of GST protein had decreased to $60 \cdot 3 \pm 4 \cdot 0 \mu \mathrm{g}$ per $\mathrm{mg}$ cytosolic protein. Although the concentration of each of the Mu-class subunits was maintained during culture, the concentration of almost all Alpha-class subunits decreased substantially during culture, whereas that of the Pi-class subunit, which is not detectable in freshly isolated hepatocytes, increased. Thus, the complement of GST subunits present in hepatocytes is altered during culture.

Treatment of co-cultured hepatocytes with testosterone or with $5 \alpha$-DHT had no significant effects on the total content of either the Alpha, Mu or Pi classes of GST subunits (Table 1), which corresponds with the results obtained from activity measurements. However, the amounts of subunits A1 and A2 were increased almost twofold in response to testosterone. Subunit A2 was also increased (about threefold) by $\mathrm{OE}_{2}$. This hormone had no significant effects on any other subunit, except for subunit P1, which was reduced by $50 \%$. Treatment of cells with hGH had no significant effects on the amounts of any of the cytosolic GST subunits.

Compared with their appropriate control co-culture, $\mathrm{T}_{3}$ and $\mathrm{T}_{4}$ reduced the total GST protein content by 60 and $70 \%$ respectively. Analysis of subunits showed that $\mathrm{T}_{3}$ reduced the total content of Alpha-class subunits, whereas $\mathrm{T}_{4}$ reduced the total content of $\mathrm{Mu}$-class subunits (Table 1). The latter was due to $80 \%$ reductions in the amounts of subunits M1 and M2. 


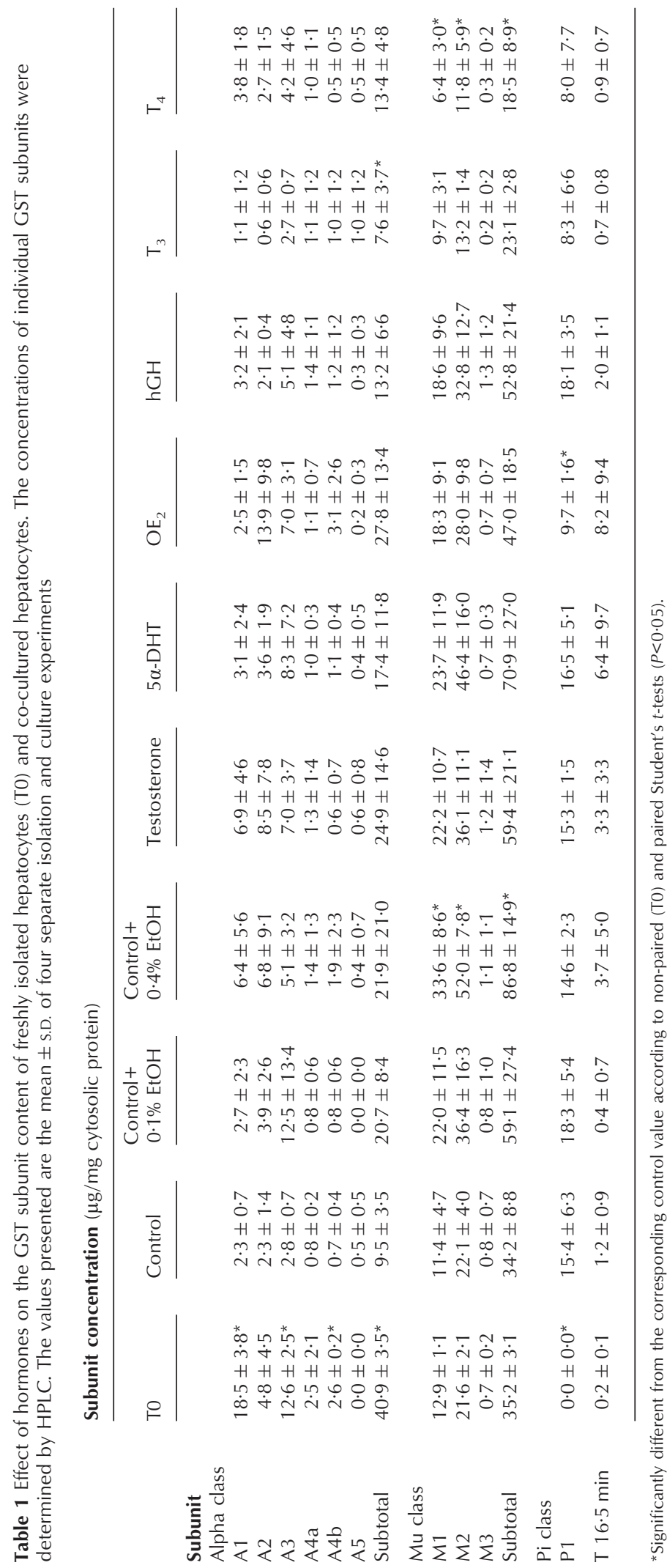


A GST A(1/2)/A3

$28 \mathrm{~S}$

B GSTM1/M2 $28 \mathrm{~S}$

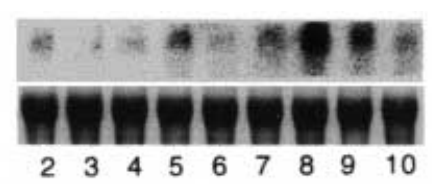

:

1

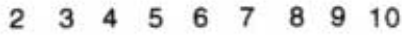

C GST P1

$28 \mathrm{~S}$
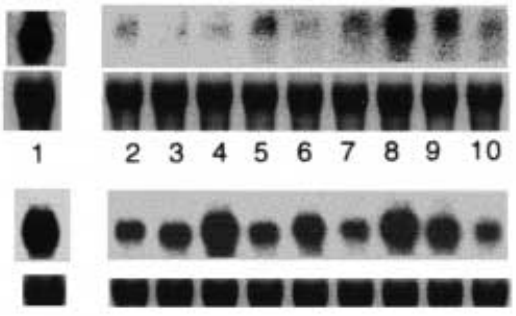

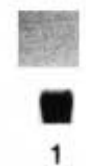

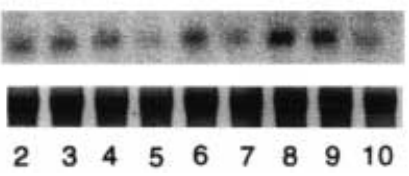

Figure 3 Northern blot analysis of mRNAs encoding GST subunits. Total RNA was isolated from freshly isolated hepatocytes (lanes 1) or from untreated co-cultured cells (lanes 2) or from co-cultured cells treated with $0 \cdot 1 \%(\mathrm{v} / \mathrm{v})$ ethanol (lanes 3$), 0 \cdot 4 \%(\mathrm{v} / \mathrm{v})$ ethanol (lanes 4), testosterone (lanes 5), $5 \alpha$-DHT (lanes 6), $\mathrm{T}_{3}$ (lanes 7), hGH (lanes 8), $\mathrm{T}_{4}$ (lanes 9) or $\mathrm{OE}_{2}$ (lanes 10). Each lane contained $15 \mu \mathrm{g}$ total RNA. Northern blots were hybridized with cloned cDNAs that hybridized to mRNAs encoding GST subunits $A(1 / 2)$ and $A 3$ (A), M1 and M2 (B) or P1 (C). In each case, a photograph of the ethidium bromide-stained gel in the region of the 28S rRNA is shown.

\section{Effects of hormones on the amounts of GST mRNAs}

To gain some insight into the levels at which the various hormones act to exert their effects on GSTs, the mRNAs encoding the GST subunits were investigated. Total RNA from freshly isolated hepatocytes and from co-cultured hepatocytes was analysed by Northern blot hybridization with cloned cDNA probes encoding GST A1/2 (which cross-hybridizes with subunit A3), GST M1 (which cross-hybridizes with subunit M2) and GST P1. Both GST (A1/2)/A3 mRNAs (Fig. 3A, lane 1) and GST M1/M2 mRNAs (Fig. 3B, lane 1) were present in freshly isolated hepatocytes, whereas GST P1 mRNA was not detectable in these cells (Fig. 3C, lane 1). Quantification of GST mRNAs showed that, in comparison with its control (Fig. 3B, lane 4), $\mathrm{T}_{4}$ (Fig. 3B, lane 9) reduced GST M1/M2 mRNA amounts by $75 \%$. This is in accord with the effects of the hormone on the amounts and activities of the corresponding GST subunits. None of the other hormones affected the amounts of mRNAs encoding the various GST subunits.

\section{Discussion}

Co-cultured adult male rat hepatocytes have been proved to be a useful model to study hormonal regulation of phase I flavin-containing mono-oxygenase activity (Coecke et al. 1998). In the present study, we used this in vitro experimental system to investigate the direct effects of various hormones on the activities and amounts of GSTs and on the amounts of the corresponding mRNAs.

Addition of $\mathrm{OE}_{2}$ to the co-cultured cells inhibited both total and Mu-class-specific GST activities, but had no effect on the abundance of $\mathrm{Mu}$-class protein or mRNA. Johnson and co-workers have reported that GST M1-1 and M1-2 activities are negatively regulated posttranslationally by methylation (catalysed by a specific GST methyltransferase) and that Mu-class subunits M1 and M2 are the preferred substrates for this enzyme in the liver (Johnson et al. 1992). Under normal physiological conditions, tissue concentrations of GSH, an inhibitor of GST methylation (Neal et al. 1988), may be sufficient to suppress GST methylation in vivo (Johnson et al. 1992). Methylation of GSTs may therefore take place only when GSH is depleted. However, previous studies from our group have demonstrated that the intracellular GSH concentration is, after an initial increase immediately after hepatocyte isolation, quickly stabilized to normal levels in co-cultures (Mertens et al. 1991, 1993b). It has, however, been shown that $\mathrm{OE}_{2}$, at physiological doses, reduces GSH concentrations in isolated hepatocytes (Ruiz-Larrea et al. 1993). It is therefore possible that the decrease in GST activities in response to treatment with $\mathrm{OE}_{2}$ (in the absence of any effect on the proteins or their mRNAs) may be mediated via post-translational methylation of GSTs. The decrease in the amount of GST subunit P1 in response to $\mathrm{OE}_{2}$ cannot account for the observed gender differences in GST amounts as this subunit is not normally present in the livers of adult rats.

In vivo studies have already demonstrated a sexual dimorphism in hepatic GSTs. In rat, total and Mu-class GST activities (Hales \& Neims 1976, Hatayama et al. 1986, Coecke et al. 1990), and the amounts of GST proteins, in particular M1 and M2 (Coecke et al. 1991, Igarashi et al. 1987), and of the corresponding mRNAs (Igarashi et al. 1987, Pickett et al. 1987, Coecke et al. 1991, Rogiers et al. 1991) are higher in male than in female liver. However, here we found no effect of the male sex hormones testosterone and $5 \alpha$-DHT on the activities or amounts of GST proteins in co-cultured male rat hepatocytes. GSTs are regulated in vivo by androgenic programming through neonatal imprinting (Lamartiniere 1981, Skett 1987), which may explain the finding that addition of androgens in vitro cannot upregulate GST activity (the male GST activity has already been imprinted at birth).

The pituitary gland appears to be important in regulating endogenous GST expression in rats. In particular, gender differences in GH secretion patterns are involved in the regulation of GSTs in vivo (Staffas et al. 1992). Continuous administration of $\mathrm{GH}$ yields a female isoenzyme pattern, whereas discontinuous administration of GH yields a male pattern (Staffas et al. 1992). A similar observation has been made for members of the cytochrome P450 family (Mode et al. 1989, Vind et al. 1992). 
However, our results indicate that in co-cultured rat hepatocytes hGH has no effect on the GST activities or amounts of GST proteins or on the amounts of the corresponding mRNAs.

Both of the thyroid hormones, $\mathrm{T}_{3}$ and $\mathrm{T}_{4}$, reduced the activities of GSTs towards CDNB and DCNB and reduced the total GST protein content. These in vitro results correspond well with earlier in vivo observations that prolonged oral administration of $\mathrm{T}_{3}$ or $\mathrm{T}_{4}$ causes a decline in GST activity in rat liver, which can be related to a decrease in the amounts of Alpha- and $\mathrm{Mu}$-class subunits (Beckett et al. 1988). Often, effects exerted by $\mathrm{T}_{4}$ are comparable to those of $\mathrm{T}_{3}$ since $80 \%$ of $\mathrm{T}_{3}$ is derived from conversion of $\mathrm{T}_{4}$ in peripheral tissue, particularly the liver (Visser 1988). We found that in the case of $\mathrm{T}_{3}$ the decrease in total GST content was due to a decrease in Alpha-class subunits, whereas $T_{4}$ reduced the Mu-class subunits. These results were confirmed at the mRNA level. As proper controls for both $\mathrm{T}_{3}$ and $\mathrm{T}_{4}$ have been used in our experiments, these apparently conflicting observations are not due to different concentrations of the vehicle used. However, it is known that part of $T_{4}$ is deactivated through extensive metabolism (Visser 1996) and since our investigation of the hormonal effects at day 10 of culture with daily changes of the medium, we believe that, because of a decrease in $\mathrm{T}_{4}$ metabolism as a function of culture time, the strong, suppressive effect of $\mathrm{T}_{4}$ on the amounts of $\mathrm{Mu}$-class subunits results from a direct effect of $\mathrm{T}_{4}$ rather than from its conversion to $\mathrm{T}_{3}$.

In conclusion, our results with respect to the activity, subunit composition and abundance of steady-state mRNAs for the various GSTs indicate that GST activity is regulated by hormones both transcriptionally and posttranslationally. Such hormone-related differences in GST expression may provide a molecular basis for tissue, gender, age and interindividual differences in the toxicity of certain xenobiotics (Lock et al. 1984, Coecke et al. 1990, 1991, Singhal et al. $1992 a, b)$. The effects of the different hormones under investigation are most pronounced for the $\mathrm{Mu}$-class GSTs. In humans, $\mathrm{Mu}$-class GSTs have attracted particular interest because $45 \%$ of the European population fails to express GSTM1, because of the presence of two null alleles (Zhong et al. 1993). GSTM1containing enzymes are very effective in deactivating mutagenic and carcinogenic epoxides (Hayes \& Pulford 1995). Moreover, GSTM1 polymorphism has been linked with the development of cancers (Harris et al. 1998, Whalen \& Boyer 1998). Therefore, it is of general importance to increase our understanding of the molecular regulation of Mu-class GSTs and, more specifically, the effect of Mu-class polymorphism on endogenous GST regulation. In this respect, human hepatocyte cultures could represent a good in vitro model. However, the limited availability of human liver tissue is still a major problem (Rogiers 1993).

\section{Acknowledgements}

We thank Gino Verleye for help with the statistical interpretation of the results, and Walter Sonck and André Callaerts for their technical assistance. This work was supported by the Belgian National Fund for Scientific Research (FWO) and the Research Council of the Vrije Universiteit Brussel (OZR).

\section{References}

Akrawi M, Rogiers V, Vandenberghe Y, Palmer CNA, Vercruysse A, Shephard EA \& Phillips IR 1993 Maintenance and induction in co-cultured rat hepatocytes of components of the cytochrome P450-mediated mono-oxygenase. Biochemical Pharmacology 45 1583-1591.

Beckett GJ, Boyd R, Beddows SE \& Hayes JD 1988 Decreased hepatic glutathione S-transferase A, AA and L concentration produced by prolonged thyroid hormone administration. Biochemical Pharmacology 37 3201-3204.

Boyer TD, Vessey DA, Holcomb C \& Saley N 1984 Studies of the relationship between the catalytic activity and binding of nonsubstrate ligands by the glutathione S-transferases. Biochemical Journal 217 179-185.

Bradford MM 1976 A rapid and sensitive method for the quantitation of microgram quantities of protein utilizing the principle of protein-dye binding. Analytical Biochemistry 72 248-254.

Chomczynski P \& Sacchi N 1987 Single-step method of RNA isolation by acid guanidinium thiocyanate-phenol-chloroform extraction. Analytical Biochemistry 162 156-159.

Coecke S, Vandenberghe Y, Callaerts A, Sonck W, Verleye G, Van Bezooijen CFA, Vercruysse A \& Rogiers V 1990 Hepatic cytosolic glutathione S-transferase activities in ageing brown Norway ratsimportance of sex differences and phenobarbital treatment for studies of ageing. Mechanisms of Ageing and Development 55 189-198.

Coecke S, Rogiers V, Callaerts A, Soetaert H, Van Bezooijen CFA, Guillouzo A \& Vercruysse A 1991 Effect of the aging process on gender and phenobarbital dependent glutathione S-transferase activity, subunit composition and steady state mRNA in Brown Norway rat liver. In Topics in Aging Research in Europe, vol 16, pp 155-163. Eds KW Woodhouse \& MS O’Mahony. Leiden: Eurage.

Coecke S, Segaert A, Vercruysse A \& Rogiers V 1993 Expression of flavin-containing monooxygenase activity in adult rat hepatocytes under various culture conditions. Toxicology In Vitro 7 487-491.

Coecke S, Debast G, Phillips IR, Shephard EA \& Rogiers V 1998 Hormonal regulation of microsomal flavin-containing monooxygenase activity by sex steroids and growth hormone in co-cultured adult male rat hepatocytes. Biochemical Pharmacology 56 1047-1051.

Croci T \& Williams GM 1985 Activities of several phase I and phase II xenobiotic biotransformation enzymes in cultured hepatocytes from male and female rats. Biochemical Pharmacology 34 3029-3035.

De Smet K, Beken S, Vanhaecke T, Pauwels M, Vercruysse A \& Rogiers V 1998 Isolation of rat hepatocytes. In Cytochrome P450 Protocols. Series in: Methods in Molecular Biology, pp 295-301. Eds Phillips IR \& Shephard EA. Totowa: Humana Press Inc.

Feinberg AP \& Vogelstein B 1983 A technique for radiolabeling DNA restriction endonuclease fragments to high specific activity. Analytical Biochemistry 132 6-13.

Fourney RM, Miyakoshi J, Day RS \& Parterson MC 1988 Northern blotting: efficient RNA staining and transfer. Bio Research Laboratories Focus 10 5-6.

Gebhardt R, Fitzke H, Fausel M, Eisenmann-Tappe I \& Mecke D 1990 Influence of hormones and drugs on glutathione-S-transferase 
levels in primary culture of adult rat hepatocytes. Cell Biology and Toxicology 6 365-378.

Habig W, Pabst M \& Jakoby W 1974 Glutathione S-transferase A. A novel kinetic mechanism in which the major reaction pathway depends on substrate concentration. Journal of Biochemistry $\mathbf{2 4 9}$ 7130-7139.

Hales B \& Neims A 1976 A sex difference in hepatic glutathione S-transferase B and the effect of hypophysectomy. Biochemical Journal $160223-229$.

Harris MJ, Coggan M, Langton L, Wilson SR \& Board PG 1998 Polymorphism of the pi class glutathione S-transferase in normal populations and cancer patients. Pharmacogenesis 8 27-31.

Hatayama I, Satoh K \& Sato K 1986 Developmental and hormonal regulation of the major form of hepatic glutathione S-transferase in male mice. Biochemical and Biophysical Research Communications 140 $581-588$.

Hatayama I, Nishimura S, Narita T \& Sato K 1993 Sex-dependent expression of class pi glutathione S-transferase during chemical hepatocarcinogenesis in B6C3F1 mice. Carcinogenesis 14 537-538.

Hayes JD \& Pulford DJ 1995 The glutathione S-transferase supergene family: regulation of GST and the contribution of the isoenzymes to cancer chemoprotection and drug resistance. Critical Reviews in Biochemistry and Molecular Biology 30 445-600.

Hiratsuka A, Sebeta N, Kawashima K, Okuda H, Ogura K, Watabe T, Satoh K, Hatayama I, Tsuchida S, Ishikawa T \& Sato K 1990 A new class of rat glutathione S-transferase Yrs-Yrs inactivating reactive sulfate esters as metabolites of carcinogenic arylmethanols. Journal of Biological Chemistry 265 11973-11981.

Igarashi T, Irokawa N, Ono S, Ohmori S, Ueno K, Kitagawa H \& Satoh T 1987 Difference in the effects of phenobarbital and 3-methylcholanthrene treatment on subunit composition of hepatic glutathione S-transferase in male and female rats. Xenobiotica 17 127-137.

Ishigaki S, Abramovitz M \& Listowsky I 1989 Glutathione Stransferases are major cytosolic thyroid hormone binding proteins. Archives of Biochemistry and Biophysics 273 265-272.

Johnson JA, Neal TL, Collins JH \& Siegel FL 1990 Characterization of methylation of rat liver cytosolic glutathione S-transferases by using reverse-phase h.p.l.c. and chromatofocusing. Biochemical Journal 270 483-489.

Johnson JA, Finn KA \& Siegel FL 1992 Tissue distribution of enzymic methylation of glutathione S-transferase and its effects on catalytic activity. Methylation of glutathione S-transferase 11-11 inhibits conjugating activity towards 1 -chloro-2,4-dinitrobenzene. Biochemical Journal 282 279-289.

Johnson JA, El Barbary AE, Kornguth SE, Brugge JF \& Siegel FL 1993 Glutathione S-transferase isoenzymes in rat brain neurons and glia. Journal of Neuroscience 13 2013-2023.

Kelley MK \& Bjeldanes LF 1995 Modulation of glutathione Stransferase activity and isozyme pattern in liver and small intestine of rats fed goitrin- and $\mathrm{T}_{3}$-supplemented diets. Food and Chemical Toxicity 33 129-137.

Kispert A, Meyer DJ, Lalor E, Coles B \& Ketterer B 1989 Purification and characterization of a labile rat glutathione transferase of the $\mathrm{Mu}$ class. Biochemical Journal $260789-793$.

Lamartiniere CA 1981 The hypothalamic-hypophyseal-gonadal regulation of hepatic glutathione S-transferases in the rat. Biochemical Journal 198 211-217.

Li N-Q \& Tu C-PD 1989 Suppression of glutathione S-transferases in rat seminal vesicles or pituitary glands. Biochemical and Biophysical Research Communications 136 1057-1062.

Listowsky I, Abramovitz M, Homma H \& Niitu Y 1988 Intracellular binding and transport of hormones and xenobiotics by glutathioneS-transferases. Drug Metabolism Reviews 19 305-318.

Lock EA, Ishmael J \& Hook JB 1984 Nephrotoxicity of hexachloro1,3-butadiene in the mouse: the effect of age, sex, strain, monooxygenase modifiers, and the role of glutathione. Toxicology and Applied Pharmacology 72 484-494.
McLellan LI \& Hayes JD 1987 Sex-specific constitutive expression of the pre-neoplastic marker glutathione S-transferase, YfYf, in mouse liver. Biochemical Journal 245 399-406.

Mankowitz L, Castro VM, Mannervik B, Rydström J \& DePierre JW 1990 Increase in the amount of glutathione transferase 4-4 in the rat adrenal gland after hypophysectomy and down-regulation by subsequent treatment with adrenocorticotrophic hormone. Biochemical Journal 265 147-154.

Mannervik B \& Danielson UH 1988 Glutathione transferases structure and catalytic activity. Critical Reviews in Biochemistry 23 283-337.

Mannervik B, Alin P \& Guthenberg C 1985 Identification of three classes of cytosolic glutathione transferase common to several mammalian species: correlation between structural data and enzymatic properties. PNAS 82 7202-7206.

Mertens K, Rogiers V, Sonck W \& Vercruysse A 1991 Reduced and oxidized glutathione contents in adult rat hepatocytes under various culture conditions. Cell Biology and Toxicology 7 101-110.

Mertens K, Rogiers V \& Vercruysse A 1993a Measurement of malondialdehyde in cultures of adult rat hepatocytes. Toxicology In Vitro 7 439-441.

Mertens K, Rogiers V \& Vercruysse A 1993 b Glutathione dependent detoxication in adult rat hepatocytes under various culture conditions. Archives of Toxicology 67 680-685.

Meyer DJ, Lalor E, Coles B, Kispert A, Alin P, Mannervik B \& Ketterer B 1989 Single-step purification and h.p.l.c. analysis of glutathione transferase $8-8$ in rat tissues. Biochemical Journal 260 785-788.

Meyer DJ, Gilmore KS, Coles B, Dalton K, Hulbert PB \& Ketterer B 1991 Letter: Structural distinction of rat GSH transferase subunit 10 (published erratum appears in Biochemical Journal 1992283 919). Biochemical Journal 274 619-623.

Meyer DJ, Harris JM, Gilmore KS, Coles B, Kensler TW \& Ketterer B 1993 Quantitation of tissue- and sex-specific induction of rat GSH transferase subunits by dietary 1,2-dithiole-3-thiones. Carcinogenesis 14 567-572.

Mode A, Wiersma-Larsson E, Strøm A, Zaphiropoulos PG \& Gustafsson J-A 1989 A dual role of growth hormone as a feminizing and masculinizing factor in the control of sex-specific cytochrome P-450 isozymes in rat liver. Journal of Endocrinology 120 311-317.

Neal TL, Wright LS \& Siegel FL 1988 Identification of glutathione S-transferase as a substrate and glutathione as an inhibitor of in vitro calmodulin-stimulated protein methylation in rat liver cytosol. Biochemical and Biophysical Research Communications 156 368-374.

Norusis MJ 1986 Storing memories, repeated measures, analysis of variance. In SPSS-PC+ Advanced Statistics, pp B152-B181. Chicago: SPSS Inc.

Okey AB 1990 Enzyme induction in the cytochrome P-450 system. Pharmacology and Therapeutics 45 241-298.

Pemble S, Taylor JB \& Ketterer B 1986 Tissue distribution of rat glutathione S-transferase subunit 7, a hepatoma marker. Biochemical Journal $240885-889$.

Pickett CB \& Lu AYH 1989 Glutathione S-transferases: gene structure, regulation, and biological function. Annual Review of Biochemistry $\mathbf{5 8}$ 734-764.

Pickett C, Telakowski C, Ding G \& Ding Y 1987 Sequence analysis and regulation of rat liver glutathione $\mathrm{S}$-transferase mRNAs. Xenobiotica 17 317-323.

Rogiers V 1993 Cultures of human hepatocytes in in vitro pharmacotoxicology. In Human Cells in In Vitro Pharmaco-Toxicology, pp 77-115. Eds V Rogiers, W Sonck, E Shephard \& A Vercruysse. Brussels: Vubpress.

Rogiers V \& Vercruysse A 1993 Rat hepatocyte cultures and co-cultures in biotransformation studies of xenobiotics. Toxicology 82 193-208. 
Rogiers V, Vandenberghe Y, Callaerts A, Verleye G, Cornet M, Mertens K, Sonck W \& Vercruysse A 1990 Phase I and phase II xenobiotic biotransformation in cultures and co-cultures of adult rat hepatocytes. Biochemical Pharmacology 40 1701-1706.

Rogiers V, Coecke S, Vandenberghe Y, Morel F, Callaerts A, Verleye G, Van Bezooijen CFA, Guillouzo A \& Vercruysse A 1991 Effect of the aging process on the gender and phenobarbital dependent expression of glutathione S-transferase subunits in brown Norway rat liver. Biochemical Pharmacology 42 491-498.

Ruiz-Larrea MB, Garrido MJ \& Lacort M 1993 Estradiol-induced effects on glutathione metabolism in rat hepatocytes. Journal of Biochemistry 113 563-567.

Rushmore TH, Morton MR \& Pickett CB 1991 The antioxidant responsive element. Journal of Biological Chemistry 266 11632-11639.

Scott TR \& Kirsh RE 1987 The isolation of a fetal rat liver glutathione S-transferase isoenzyme with high glutathione peroxidase activity. Biochimica et Biophysica Acta 926 264-269.

Singhal SS, Saxena M, Ahmad H \& Awasthi YC 1992a Glutathione S-transferase of mouse liver: sex-related differences in the expression of various isozymes. Biochimica et Biophysica Acta 1117 105.

Singhal SS, Saxena M, Ahmad H, Sharma R \& Awasthi YC $1992 b$ Glutathione S-transferases of mouse liver: sex-related differences in the expression of various isozymes (published erratum appeared in Biochimica et Biophysica Acta 19921117 105). Biochimica et Biophysica Acta 1116 137-146.

Skett P 1987 Hormonal regulation and sex differences of xenbiotic metabolism. In Progress in Drug Metabolism, vol 10, pp 85-140. Eds JW Bridges, LF Chasseaud \& GG Gibson. London: Taylor and Francis Ltd.

Skett P \& Paterson P 1985 Sex differences in the effects of microsomal enzyme inducers on hepatic phase I drug metabolism in the rat. Biochemical Pharmacology 34 3533-3536.

Staffas L, Mankowitz L, Söderström M, Blanck A, Porsch-Hällström I, Sundberg C, Mannervik B, Olin B, Rydström J \& Depierre JW 1992 Further characterization of hormonal regulation of glutathione transferase in rat liver and adrenal glands. Sex differences and demonstration that growth hormone regulates the hepatic levels. Biochemical Journal 286 65-72.

Tsuchida S \& Sato K 1992 Glutathione transferases and cancer. Critical Reviews in Biochemistry and Molecular Biology 27 337-384.

Vandenberghe Y, Glaise D, Meyer DJ, Guillouzo A \& Ketterer B $1988 b$ Glutathione transferase isoenzymes in cultured rat hepatocytes. Biochemical Pharmacology 37 2482-2485.

Vandenberghe Y, Ratanasavanh D, Glaise D \& Guillouzo A 1988a Influence of medium composition and culture conditions on glutathione S-transferase activity in adult rat hepatocytes during culture. In Vitro Cell Developmental Biology 24 281-288.
Vandenberghe Y, Foriers A, Rogiers V \& Vercruysse A 1990 Changes in expression and 'de novo' synthesis of glutathione S-transferase subunits in cultured adult rat hepatocytes. Biochemical Pharmacology 39 685-690.

Vandenberghe Y, Tee L, Morel F, Rogiers V, Guillouzo A \& Yeoh G 1991 Regulation of glutathione S-transferase gene expression by phenobarbital in cultured adult rat hepatocytes. FEBS Letters 284 103-108.

Vanhaecke T, De Smet K, Beken S, Pauwels M, Vercruysse A \& Rogiers V 1998 Rat hepatocyte cultures. In Cytochrome P450 Protocols. Series in: Methods in Molecular Biology, pp 311-317. Eds IR Phillips \& EA Shephard. Totowa: Humana Press Inc.

Vind C, Dich J \& Grunnet N 1992 Regulation by growth hormone and glucocorticoid of testosterone metabolism in long-term cultures of hepatocytes from male and female rats. Biochemical Pharmacology 44 1523-1528.

Visser TJ 1988 Metabolism of thyroid hormone. In Hormones and Their Actions, part I, pp 81-104. Eds BA Cooke, RJB King \& HJ van der Molen. Amsterdam: Elsevier Science Publishers B.V. (Biomedical Division).

Visser TJ 1996 Pathways of thyroid hormone metabolism. Acta Medica Austriaca 23 10-16.

Vos RME \& Van Bladeren PJ 1990 Glutathione S-transferases in relation to their role in the biotransformation of xenobiotics. Chemico-Biological Interactions 75 241-265.

Whalen R \& Boyer TD 1998 Human glutathione S-transferases. Seminars in Liver Disease 18 345-358.

Wilce MJC \& Parker MW 1994 Structure and function of glutathione S-transferases. Biochimica et Biophysica Acta 1205 1-18.

Williams GM \& Gunn JM 1974 Long-term cell culture of adult rat liver epithelial cells. Experimental Cell Research 89 139-142.

Xia C, Taylor JB, Spencer SR \& Ketterer B 1993 The human glutathione S-transferase P1-1 gene: modulation by retinoic acid and insulin. Biochemical Journal 292 845-850.

Xia C, Hu J, Ketterer B \& Taylor JB 1996 The organization of the human GSTP1-1 gene promotor and its response to retinoic acid and cellular redox status. Biochemical Journal 313 155-161.

Zhong S, Spurr NK, Hayes JD \& Wolf CR 1993 Deduced amino acid sequence, gene structure and chromosomal location of a novel human class Mu glutathione S-transferase, GSTM4. Biochemical Journal 291 41-50.

Received 8 July 1999

Revised manuscript received 6 March 2000

Accepted 3 April 2000 